\title{
TEORIAS DA SENSAÇÃO EM PESSOA E BERGSON
}

Resumo: O artigo explora aspectos do Sensacionismo, movimento da vanguarda portuguesa iniciado na Revista Orpheu por Fernando Pessoa e Mário de Sá-Carneiro -, tendo como foco explorar proximidades entre o conceito pessoano de sensação e aquele formulado pela filosofia de Henri Bergson (1859-1941). Explicitando as possíveis relações do pensamento do filósofo francês com aquele de Pessoa, teorizado e experimentado pelo poeta em sua obra tanto poética quanto crítica, tem-se como objetivo destacar a atualidade e a pertinência do conceito de sensação de Pessoa para as reflexões filosóficas e poéticas da atualidade.

Palavras-chave: Sensação; Fernando Pessoa; Filosofia; Henri Bergson.

\section{THEORIES OF SENSATION IN PESSOA AND BERGSON}

Abstract: The article explores aspects of Sensationism, the Portuguese vanguard movement which began in the magazine Orpheu by Fernando Pessoa and Mário de Sá-Carneiro, by focusing on the proximities between Pessoa's concept of sensation and the one formulated by Henri Bergson (1859-1941). Pointing out the relation between the French philosopher's thought and Pessoa's, the aim is to highlight the relevance of Pessoa's concept of sensation for the philosophical reflexions and poetics nowadays.

Key words: Sensation; Fernando Pessoa; Philosophy; Henri Bergson.

Talvez não seja preciso reiterar, uma vez mais, o quanto Fernando Pessoa foi "um poeta impulsionado pela filosofia", como ele mesmo formulou. ${ }^{2} \mathrm{Nem}$ o quanto ele se encaixa na ideia de que o poeta moderno tem como característica ser, justamente, esse poeta crítico, que não somente pensa como tematiza o fazer poético. Dando esses fatos como conhecidos e aceitos por todos nós, parto para a questão que impulsionou o presente estudo, acerca do que poderíamos talvez chamar de uma "doutrina das sensações" ou “metafísica das sensações” em Pessoa, nos termos de José Gil (1996): a proximidade que se

\footnotetext{
${ }^{1}$ Professora-doutora do Programa de Estudos Pós-Graduados em Literatura e Crítica Literária da PUC-SP. Doutora em Teoria e História Literária pela Unicamp.

2 "Eu era um poeta impulsionado pela filosofia, não um filósofo dotado de faculdades poéticas. Adorava admirar a beleza das coisas, descortinar no imperceptível, através do que é diminuto, a alma poética do universo." (PESSOA, 1966, p. 14)
} 


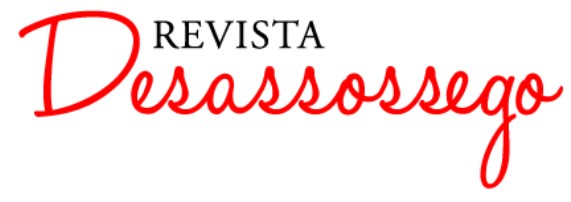

DESASSOSSEGO 15 | JUN/2016 | ISSN 2175-3180

DOI: http://dx.doi.org/10.11606/issn.2175-3180.v8i15p140-153

mostrava entre a concepção de Pessoa, acerca da sensação, e aquela que encontramos na filosofia de Henri Bergson (1859-1941).

Seria Pessoa um leitor de Bergson? Para um leitor da filosofia mais recente, em especial aquela que parte de Bergson e segue por Gilles Deleuze e Félix Guattari, intriga a grande coincidência entre a concepção pessoana acerca de certos conceitos - como os de sensação, consciência, tempo e memória. Coincidência esta que parece ir além de uma afinidade, como encontramos por exemplo no caso de Pessoa com outros filósofos, como Nietzsche, por exemplo. Daí a ideia de explorar um pouco essas teorias da sensação em Pessoa e Bergson.

Enquanto em Bergson temos um pensamento filosófico sistematizado, em Pessoa sabemos que a teoria da sensação é uma teoria inacabada, é uma promessa de teoria, promessa de um livro teórico que tratasse do Sensacionismo, mas que Pessoa não chegou a concluir. Para entender o Sensacionismo, esse movimento, esse "ismo" criado por Pessoa, temos de seguir pistas, juntar pedaços, buscar encaixar peças, de fragmentos de textos esparsos, que pouco a pouco descobertos em sua arca, e que podem vir a compor uma certa teoria e, quem sabe, uma certa filosofia até.

Mas se o Sensacionismo é uma teoria inacabada, no sentido dos textos teóricos de Pessoa, talvez seja uma teoria muito bem "executada" nos poemas pessoanos. Conhecer a teoria da sensação em Pessoa é como montar um quebra-cabeças, e se deve jogar tanto com aquilo que ele falou sobre, como com aqueles momentos em que ele operon com a própria teoria, fazendo-a funcionar em sua prática dos poemas. É o que encontramos sobretudo na poesia de Álvaro de Campos, o heterônimo mais sensacionista, mas também nos textos-fragmentos do Livro do desassossego, em grande parte atribuído ao semiheterônimo Bernardo Soares. Temos nesses textos a execução da proposta sensacionista, não somente sua exemplificação, mas sua elaboração mesmo, em uma poesia e prosa muito reflexivas. Assim, muito do que Pessoa teorizou está nos poemas de Campos e nos fragmentos que comporiam o Livro do desassossego, que seria como que um "laboratório" poético, como disse primeiro Jacinto do Prado Coelho, em relação aos heterônimos, e depois José Gil, referindo-se, especialmente nas páginas de Fernando Pessoa ou a metafísica das sensações, ao laboratório de sensações que estaria em curso nesses fragmentos.

Em Campos, por exemplo temos momentos de formulação teórica mesmo, como no conhecido poema: 
Afinal, a melhor maneira de viajar é sentir.

Sentir tudo e de todas as maneiras.

Sentir tudo excessivamente

Porque todas as coisas são, em verdade excessivas

E toda a realidade é um excesso, uma violência,

Uma alucinação extraordinariamente nítida

Que vivemos todos em comum com a fúria das almas,

O centro para onde tendem as estranhas forças centrífugas

Que são as psiques humanas no seu acordo de sentidos.

Quanto mais eu sinta, quanto mais eu sinta como várias pessoas,

Quanto mais personalidades eu tiver,

Quanto mais intensamente, estridentemente as tiver,

Quanto mais simultaneamente sentir com todas elas,

Quanto mais unificadamente diverso, dispersadamente atento,

Estiver, sentir, viver, for,

Mais possuirei a existência total do universo, (...) (PESSOA, 2005, p. 406)

Esse poema resume bem o programa do Sensacionismo: sentir tudo e de todas as maneiras. E seu argumento central para isso, que é: quanto mais eu sinta, e quanto mais sinta pelo mais variado número e tipo de pessoas, mais completo serei, enquanto poeta, mais possuirei a multiplicidade que compõe o universo.

O Sensacionismo então, como doutrina das sensações, só pode ser um movimento que abarca o maior número possível de modos de sentir e de ser, modos mesmo contraditórios, dissonantes, diversos. Daí também o Sensacionismo ser um movimento que, diz Pessoa, abarcaria todos os outros. Abarcar a realidade, para o sensacionista, é abarcar o excesso inapreensível que compõe o real, é ser consciente da violência que as sensações do real impõem ao nosso corpo, e não buscar compreender o universo - ou ainda, buscar vivê-lo, justamente, em sua incompreensibilidade e discordâncias internas: "a realidade é a incompreensibilidade das coisas", dirá Pessoa.

Nos fragmentos em prosa mais teórica, vamos encontrar o que seria a premissa básica do Sensacionismo, que é a ideia de que a realidade se resume às sensações: "A sensação como realidade essencial", diz um dos textos; "A única realidade é a sensação", diz outro; "O Sensacionismo afirma, primeiro, o princípio da primordialidade da sensação - que a sensação é a única realidade para nós”. E, como ele dirá, isso não terá consequência alguma sobre o sentido das coisas, trata-se apenas de constatar que, na realidade, não temos nada além de sensações:

Ficamos portanto com as nossas sensações por única 'realidade', inútil que realmente tem aqui certo valor, mas é uma conveniência para frasear. 


\section{Disiandengy}

DESASSOSSEGO 15 ｜ JUN/2016 | ISSN 2175-3180

DOI: http://dx.doi.org/10.11606/issn.2175-3180.v8i15p140-153

De 'real' temos apenas as nossas sensações, mas 'real' (que é uma sensação nossa) não significa nada, nem mesmo 'significa' significar qualquer coisa, nem sensação tem um sentido, nem 'tem um sentido' é coisa que tenha sentido algum. (PESSOA, 1968, p. 218)

Em outro momento, Pessoa concluirá que ele mesmo seria uma sensação sua, não estando nem mesmo seguro de sua própria existência:

A única realidade para mim são as minhas sensações. Eu sou uma sensação minha. Portanto nem da minha própria existência estou certo. Posso está-lo apenas daquelas sensações a que eu chamo minhas.

A verdade? É uma coisa exterior? Não posso ter a certeza dela, porque não é uma sensação minha, e eu só destas tenho a certeza. (PESSOA, 1968, p. 220)

Decorrência direta dessa reflexão, de cunho evidentemente filosófico, veremos nos fragmentos sobre Sensacionismo a formulação de que "A base de toda a arte é a sensação". Em toda sua extensão, a frase abarca tanto a ideia de que o material do artista é a sensação quanto a de que a vivência da arte, para o público, é a sensação. Ou seja, que a arte seja feita a partir de e visando a sensação. E o que estará pressuposto no projeto de Pessoa, a ideia de que a poesia se dirige à sensação do leitor, ou como diz Álvaro de Campos (em "Apontamentos para uma estética não-aristotélica"), o poeta deve forçar o leitor a sentir o que ele sentiu. O poema é um objeto de provocar sensações. Aí, portanto, reside todo o trabalho de composição do poeta sensacionista. Ele é o poeta que, tendo consciência disso e fazendo dessa constatação o cerne de seu trabalho, deverá operar uma transmutação da sensação comum em sensação artística, estética. A descrição do processo de composição do poema aparece em alguns fragmentos de Pessoa e ela obedece, grosso modo, três etapas que dizem respeito ao que ele chama de uma intelectualização ou abstração da sensação. Para se tornar uma sensação estética, ou para estetizar a sensação, é preciso, portanto, submetê-la a uma espécie de "tratamento", que é uma análise. As três etapas fundamentais dessa análise seriam: 1) A sensação como tal; 2) a consciência dessa sensação; 3) a consciência da consciência da sensação ou 1) sinto; 2) sei que sinto; 3) sei que sei que sinto.

E assim, progressivamente, o poeta vai operando uma análise das sensações, diz Pessoa, de modo a transformar a sensação inicial em uma sensação intelectualizada - que nada mais é do que uma sensação que foi tomada como tal e esmiuçada, decomposta em seus elementos, pelo poeta. Apesar desses termos "intelectualização", "consciência", vemos o esforço de Pessoa por engendrar um processo em que as dicotomias razão X emoção 
sejam suprimidas. É preciso sentir, antes de tudo, mas é preciso - para ser poeta - saber explorar, esmiuçar e tornar, mais uma vez, sensível aquilo que se sentiu, renovando o ciclo interminável das sensações. E isso mesmo, ou justamente, às custas de transformar a sensação inicial em outra ou outras sensações, proliferando as sensações:

\section{[Sensacionismo] \\ Princípios}

1. Todo o objecto é uma sensação nossa.

2. Toda a arte é a conversão duma sensação em objecto.

3. Portanto, toda a arte é a conversão duma sensação numa outra sensação. (PESSOA, 1966, p. 168.) $)^{3}$

Esse tratamento da sensação implica, assim, o uso da inteligência ou da consciência, para que a sensação inicial seja sintetizada de modo a ser capaz de se descolar da experiência inicial, subjetiva - e se torne, desse modo, uma sensação mais coletiva e impessoal: essa que é a sensação artística. Nesses trechos retirados de carta a um editor inglês, Pessoa diz:

1- A única realidade da vida é a sensação. A única realidade em arte é a consciência da sensação.

2- (...) $\mathrm{Na}$ arte existem apenas sensações e a consciência que dela temos. (...)

3- A arte, na sua definição plena, é a expressão harmônica da nossa consciência das sensações, ou seja, as nossas sensações devem ser expressas de tal modo que criem um objeto que seja uma sensação para os outros. A arte não é, como Bacon disse, 'homem adicionado à Natureza'; é a sensação multiplicada pela consciência - multiplicada, ela será bem notada. (PESSOA, 1966, p. 130-131, tradução nossa) ${ }^{4}$

Pessoa chamará esse tipo específico de sensação, a artística, de "sensação do abstrato". Já deslocada do sujeito que a sentiu e do objeto que a disparou, a sensação ganha terreno e abre novos lugares, novas conexões e se traduz em novas imagens. As sensações do abstrato, "resultantes do trabalho mental" (PESSOA, 1966, p. 190), ou multiplicadas pela consciência, são aquelas verdadeiramente estéticas, porque não mais apenas empíricas e não mais atadas aos estados de coisa que lhe deram origem. São elas que poderão se

\footnotetext{
3 Provavelmente de 1916.

${ }^{4}$ Texto originalmente em inglês: "The only reality in life is sensation. The only reality in art is consciousness of the sensation. / 2. (...) In art there are only sensations and our consciousness of them. (...) / 3. Art, fully defined, is the harmonic expression of our consciousness of sensations; that is to say that they create an object which will be a sensation to others. Art is not, as Bacon said, 'man added to Nature'; it is sensation multiplied by consciousness - multiplied, be it well noted."
} 


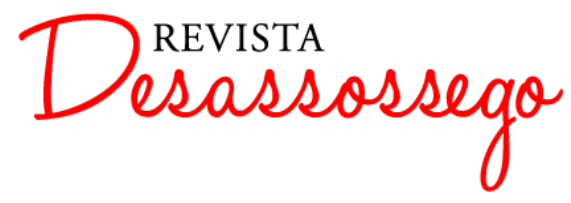

DESASSOSSEGO 15 | JUN/2016 | ISSN 2175-3180

DOI: http://dx.doi.org/10.11606/issn.2175-3180.v8i15p140-153

transportar à vivência do leitor que poderão constituir, como ele diz no trecho destacado acima, "um objeto que seja uma sensação para os outros".

Quando Pessoa chega à formulação das sensações do abstrato, encontramos um eco do conceito de Bergson acerca da sensação, que talvez nos ajude a compreender o que o poeta vislumbrava. Parece que, nesse momento, o conceito de Pessoa aproxima-se do que é a natureza da sensação para Bergson: uma natureza inextensiva ou intensiva. A sensação seria uma "qualidade pura", e, portanto, não mensurável e não passível de comparações. Segundo Bergson, em Ensaio sobre os dados imediatos da consciência, acostumamo-nos a crer que as sensações são dados quantitativos - que uma dor pode ser apenas maior ou menor -, acostumamo-nos a compreender intensidade no sentido de grandeza e não de singularidade. Mas a sensação não seria extensa e, portanto, não poderia aumentar ou diminuir. O homem traduz a sensação para si, então, como algo mensurável e, portanto, homogêneo. É o modo que ele tem de conseguir conceber a sensação que, em sua natureza própria, seria apenas algo da ordem das forças.

Bergson dirá que reportamos sempre as sensações às suas supostas causas exteriores (2003, p. 15). Acostumamo-nos a atar as sensações às suas fontes, as causas, que são extensas: o fogo, o gelo, as ondas sonoras, uma pluma ou um saco de areia, uma superfície mais ou menos áspera, um objeto maior ou menor..., são coisas concretas que afetam nossos sentidos e disparam as sensações. As causas possuem grandezas, são objetos mais ou menos pesados, maiores ou menores, etc. E nossos músculos também são extensos e respondem com maior ou menor contração ou distensão. Por isso temos o hábito de sempre associar a sensação a essas coisas, para que possamos concebê-la (2003, p. 18).

No entanto, as sensações em si são inextensas, não ocupam o espaço; elas são forças, são intensidades puras que se dão em nosso corpo e não teriam, portanto, como possuir grandezas, extensões. Elas são efeitos das contrações musculares, das ondas nervosas, mas não se localizam estritamente aí, são antes uma ponte de ligação entre o corpo e os sentimentos, emoções. Bergson defende que, se suprimíssemos esse nosso hábito de dar extensão às sensações, reportando-as às suas causas extensas, empíricas, veríamos que cada uma delas na verdade é uma qualidade pura, incomparável, única e irrepetível. Daí ser o meio das sensações um meio heterogêneo, em que as mudanças se dão por saltos qualitativos, uma sensação, ao se modificar, muda de natureza e não de grandeza 
(BERGSON, 2003, p. 31). As sensações são forças singulares - forças e intensidades não compreendidas aqui no sentido de grandezas extensas, mas de qualidades puras.

É essa singularidade de cada sensação, isso que faz com que cada uma delas tenha como que uma coloração diferente e própria, que interessa a Bergson assinalar. Parece-me que, no processo de análise das sensações proposto por Pessoa, é também esse caráter singular e cada vez mais específico de cada sensação que caberia ao poeta explorar. Ao propor que as sensações precisam ser transformadas em sensações abstratas, Pessoa reporta-se à natureza intensiva da sensação, o poeta é aquele que conseguiria tirar um "raio x" da sensação, enxergando-a apenas em suas linhas de força, em seu movimento puro, irredutível à régua da medida. Irredutível também ao estado de coisas, aos fatos extensos, mundanos, que lhe disparou. Em um dos poucos artigos que fazem uma relação entre o poeta e Bergson, Rodrigo Fonseca Rodrigues corrobora essa ideia, dizendo:

Em consonância com Bergson, Fernando Pessoa nos diz que as sensações são incomunicáveis, intransmissíveis e incógnitas, que não têm significado nem valor, muito menos um sentido. A sensação tem realidade, pode-se dizer, de uma ubiquidade sem nenhum lugar (RODRIGUES, 2007, p.161).

Ao explicar o que seriam essas sensações do abstrato para Pessoa, José Gil dará o exemplo de um texto, do Livro do desassossego, no qual Pessoa separa a sensação de velocidade do carro em que ela se dá. Ele, portanto, descola a velocidade - que é o puro movimento - do objeto em que ela se encarna, o carro:

Para sentir a delícia e o terror da velocidade não preciso de automóveis velozes nem de comboios expressos. Basta-me um carro eléctrico e a espantosa faculdade de abstracção que tenho e cultivo.

Num carro eléctrico em marcha eu sei, por uma atitude constante e instantânea de análise, separar a ideia de carro da ideia de velocidade, separá-las de todo, até serem coisas-reais diversas. Depois, posso sentirme seguindo não dentro do carro mas dentro da mera-velocidade dele. (...) (PESSOA, 1990, p. 193)

A análise das sensações leva Pessoa a separar o carro da velocidade, de modo que cada um deles se torna uma "coisa-real" diversa. Assim, ele pode dizer sentir-se dentro da velocidade, e não do carro. Podemos dizer que, nesse caso, a velocidade é tomada enquanto uma força pura, puro movimento, como se Pessoa descesse ao nível das forças e nos fizesse vivenciar a própria velocidade como um ser independente. A velocidade em si é inextensiva, ela é uma força, ela precisa de um corpo sólido, extenso, para se dar - o carro, 


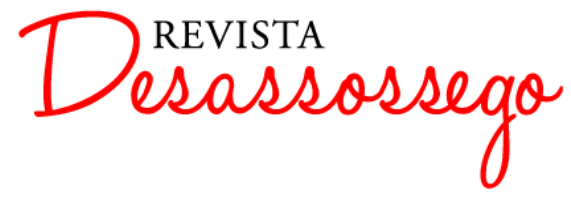

DESASSOSSEGO 15 | JUN/2016 | ISSN 2175-3180

DOI: http://dx.doi.org/10.11606/issn.2175-3180.v8i15p140-153

o comboio, as rodas, os nossos pés, etc. Em uma experiência comum, empírica, não temos como separar essas coisas, a roda da sua velocidade, pois o movimento só é sentido por nós porque ele é encarnado nos corpos, na extensão do espaço que os corpos ocupam, diz Bergson. As forças são vivenciadas por nós a partir dos corpos físicos, extensos, em que elas se encarnam e se tornam sensíveis. Por isto, para se fazer poesia, acredita Pessoa, é preciso antes descer ao nível dessas forças e ver que elas mesmas possuem uma realidade, como que uma realidade neutra e impessoal - e que serve de material para a arte. Trata-se de aprender a jogar com essas forças, para depois ser capaz de fornecer imagens novas, capazes de renovar o ciclo sensacionista.

É através do que ele chamará de "consciência" que o poeta irá operar a sensação, extraindo as ditas "sensações do abstrato". É a consciência que extrai a singularidade da sensação, ou seu perfil, suas linhas de funcionamento; como diz José Gil: "Fernando Pessoa insiste muito no caráter abstrato da arte: intelectualizar a sensação é abstrair dela um perfil, uma linha que permita ligá-la a outras sensações ou conteúdos psíquicos; (...)” (GIL, s/d, p. 38) É portanto a sensação "abstratizada" que possui a potência de se ligar a outras sensações e produzir novas imagens, novos objetos, que provoquem novas sensações no leitor.

Há uma proximidade, assim, do conceito de consciência em Pessoa e Bergson. Em Bergson é justamente a consciência que separa o homem da vivência da pura sensação. Só poderíamos viver plenamente esse continum de sensações a que estamos submetidos, esse puro movimento, se não tivéssemos a consciência. A consciência é aquilo que opera no homem e provoca uma cisão, e faz com que nos separemos de nossa experiência, que é a pura duração, tempo puro, heterogêneo, que o corpo vive como puro desenrolar das sensações. A sensação é apenas intensiva, mas nós, seres humanos e de linguagem, precisamos colocá-la em extensão para poder compreendê-la, concebê-la. Todo o programa de Alberto Caeiro situa-se aqui, nisto que oporia o pensar e o sentir, a consciência e a sensação, e na superação da dicotomia que apenas o "mestre dos heterônimos" poderia ter operado em sua plenitude. Caeiro materializa o ideal sensacionista ao mesmo tempo em que o contradiz: ele é o poeta que não precisa "de um corredor de palavras" para acessar a sensação, é o poeta que consegue ver a novidade de 


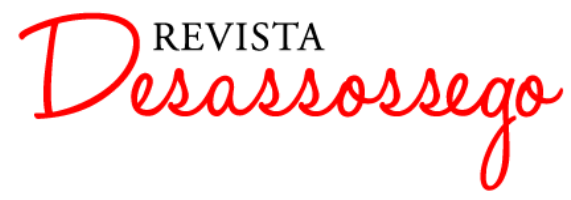

DESASSOSSEGO 15 | JUN/2016 | ISSN 2175-3180

DOI: http://dx.doi.org/10.11606/issn.2175-3180.v8i15p140-153

cada sensação, a singularidade de cada uma delas - singularidade tal que é sempre irredutível ao conceito e à linguagem. ${ }^{5}$

Em Pessoa, a consciência das sensações equivale justamente ao processo a que o poeta deve se submeter, voluntariamente. Já que o homem é inevitavelmente consciente e se separa da experiência, não há outro caminho ao poeta, se ele não é Caeiro, senão submeter-se a fundo nesse processo de conscientização, levando às últimas consequências o esmiuçar das sensações. No entanto, é preciso salientar que se trata em Pessoa de uma "consciência que se desprende do eu", como diz Gil (s/d, 63), ou seja, não se trata de uma consciência subjetiva, o que talvez aproximasse mais o poeta de uma visão fenomenológica. Analisar as sensações é cada vez fazer com que essa consciência dessubjetivada atue mais e mais, dando extensão às sensações que, em sua natureza, são inextensivas, e, portanto, inexprimíveis, e mesmo impensáveis. Esmiuçar as sensações é, portanto, penetrar no nó complexo que compõe cada sensação e destrinchar esse nó.

A consequência dessa visão, de que as sensações são forças, intensidades puras, é que elas podem se conservar inteiramente, passar de um suporte a outro. Afinal, elas não possuem grandeza - não aumentam ou diminuem, não enfraquecem com o passar do tempo (elas apenas mudam de natureza, mas então se tornam outras sensações - não há grau na sensação). Essa ideia terá consequência direta na concepção da memória e do tempo em Bergson. Não teremos como detalhar essa questão aqui, mas apenas sugerir nosso ponto de chegada ao associar as teorias da sensação de Pessoa e Bergson: a ideia de que a sensação, qualidade pura e irredutível, se conserva em nosso corpo e coexiste com nosso presente a todo instante. Achamos que a percepção vem antes da recordação, mas, na verdade, não há percepção sem recordação. Nosso olhar atua sempre junto com essas memórias. Nosso passado se conserva enquanto sensação, em nosso corpo, e coexiste com os acontecimentos presentes a todo tempo. Será esse o aspecto destacado por Eduardo Prado Coelho, o fato de que - para Bergson e em Pessoa - "a recordação não é uma percepção enfraquecida (...) Vivemos continuamente acompanhados por esse passado em si mesmo" (2012, p. 343).

Nesse ensaio, "O viajante do inverso", Coelho chama a atenção para a independência das sensações puras em relação aos fatos biográficos que lhes deram origem, a pouca

\footnotetext{
${ }^{5}$ A respeito da imanência absoluta presente no projeto de Caeiro, precisamos reportarmo-nos a mais um estudo de José Gil, Diferença e negação na poesia de Fernando Pessoa (2000).
} 
importância dos fatos biográficos em si para Pessoa. O trabalho de analisar a sensação é esse que arranca e desdobra as forças, fazendo com que elas ganhem uma vida independente de um sujeito e de um objeto. Os fatos empíricos funcionam apenas como disparadores de sensações. Pessoa trabalha com a dimensão intensiva da sensação, sua singularidade irredutível aos estados de coisa. $\mathrm{Na}$ visão bergsoniana, os fatos em si, que são extensos, podem ir ficando "para trás", implicam uma concepção linear do tempo - o tempo projetado no espaço (na extensão do relógio, do calendário). Mas a sensação em si, o passado puro, de natureza intensiva, não tem como se dissipar. Ela compõe o tempo da duração, tentativa de Bergson de propor uma outra leitura do tempo, um tempo heterogêneo, sem extensão, em que o instante presente convoca a todo tempo e, portanto, coexiste, com sensações passadas. Parece que é esse tempo da duração pura que seria o tempo da poesia para Pessoa. Nosso corpo é um composto de sensações, diria Pessoa, que possuem vida própria, que brigam entre si, se contradizem, se modulam. E cabe ao poeta, segundo o Sensacionismo, trabalhar com esse material intensivo das sensações, explorá-las e proliferá-las ao máximo, criando novas realidades.

De algum modo, neste processo de análise, o poeta retira a sensação de seu fluxo temporal e lhe dá extensão, promovendo inclusive uma existência imagética às sensações. É, portanto, um processo paradoxal: o único modo que o homem tem de se aproximar da natureza qualitativa, intensiva da sensação é proliferar ao máximo a expressão carnal da sensação. Seja penetrando nas “sensações de coisas mínimas', como diz um dos textos recolhido no Livro do desassossego, seja fabulando novas sensações associadas, como diz Pessoa em uma das instruções sobre o Sensacionismo, seja seguindo por associação e desmontando o que ele chama de "cubo das sensações" - sempre o que está em jogo é uma "concretização abstrata", como ele diz, ou uma "abstração concreta".

De modo que todo esse processo de análise tem como objetivo recolocar a sensação em seu fluxo temporal, reinstalar o movimento puro, que o poema possa ser uma vivência da "pura duração", se pensarmos no tempo para Bergson. Tempo que é a pura continuidade, heterogênea, em que as sensações se encadeiam e se modulam, sendo cada uma pura intensidade, não-extensa. Mas, como diz Bergson, o tempo só é concebido pelo homem se colocado no espaço: precisamos espacializar o tempo para poder pensá-lo. Colocamos o tempo na extensão do relógio, do calendário, contamos o tempo... enquanto que ele seria de fato e apenas uma pura intensidade inextensiva. Contar o tempo equivale a 
lhe dar extensão, assim como doamos extensão às sensações remetendo-lhes às suas causas, aos objetos que as disparam como efeito.

Para o poeta o problema seria então: como recolocar a sensação em sua duração? Como expressar o movimento? A questão toda para Pessoa parece ser como utilizar esse processo de estender as sensações, espacializar as intensidades, dar-lhes nova carne, mas ao mesmo tempo fazendo com que elas possam manter algo de seu inexprimível, de seu puro estado intensivo. É preciso que as sensações sejam analisadas, tornem-se abstratas, mas é preciso, ao mesmo tempo, que elas sejam capazes de criar um objeto de sensação, ou seja, capazes de atuar novamente como disparadores de intensidades puras.

Temos de concordar com José Gil ainda quando ele diz que Pessoa busca em sua poesia o movimento, o fluxo do tempo vivo: "Tudo o que fixa, imobiliza, repete ou enquista, o horroriza" (s/d, p. 215) e, ainda, quando associa o movimento do desassossego é um movimento que "recusa a fixação", é o movimento mesmo da vida (GIL, s/d, p. 29). O passado aparece como um fardo para Pessoa, pois ele está fixo: “Ter já existido é um peso para aquele que gostaria de libertar completamente a vida da sua inércia e o tempo da sua entropia". É preciso, portanto, operar com o passado de modo a colocá-lo de novo em movimento, esmiuçar as sensações para recolocá-las em fluxo, renovando o ciclo das sensações que é o ciclo mesmo da vida.

\section{Nota final}

Não se verifica a presença de muitos estudos que esclareçam a relação que efetivamente Pessoa teria travado com a filosofia de Bergson. Há o importante e extenso trabalho de José Gil, mas que parte sobretudo da filosofia de Gilles Deleuze (que em certos aspectos é quase uma continuação de Bergson); o ensaio de Eduardo Prado Coelho "O viajante do inverso", e o artigo do brasileiro, Rodrigo Fonseca e Rodrigues, “A poética como pensamento da sensação", que liga mais diretamente Pessoa a Bergson. No mais, encontram-se apenas aproximações pontuais, em estudos que em geral lançam mão de um ou outro conceito de Bergson como chave para ler Pessoa - como por exemplo o artigo de Burghard Baltrusch, que cita a "função fabuladora" de Bergson para dizer que a estética de Pessoa proporia uma "totalitée fabulatrice como forma do ser" (BALTRUSCH, 1999, p.7185). No entanto, de modo geral, não se encontram estudos que esclareçam se essa sintonia 


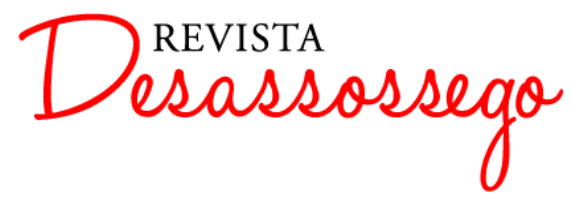

DESASSOSSEGO 15 | JUN/2016 | ISSN 2175-3180

DOI: http://dx.doi.org/10.11606/issn.2175-3180.v8i15p140-153

verificada entre as concepções pessoanas e bergsonianas acerca do tempo e da sensação decorreriam de leituras que o poeta teria realizado do filósofo.

No que foi possível se verificar até o momento, Pessoa muito provavelmente leu o filósofo francês no original - o breve Ensaio sobre os dados imediatos da consciência, publicado em 1889, quando Pessoa tinha apenas 1 ano de idade, teria chegado às mãos de Pessoa, talvez ao lado de Matéria e memória (1896) e O riso (1899), outros dois livros importantes de Bergson. Essa menção aos livros que Pessoa teria lido, encontra-se em uma matéria publicada por Jerónimo Pizarro, no Jornal i (novembro de 2009), quando da publicação de novos inéditos de Pessoa em Portugal. Em uma nota, o pesquisador comenta acerca de Bergson que "A julgar por alguns vestígios, Pessoa talvez tenha tido um conhecimento parcial de...”, e cita essas três obras de Bergson.

Entretanto, dentre os livros de sua biblioteca particular que foram doados à Casa Fernando Pessoa, e foram digitalizados e disponibilizados no site da instituição, não constam livros de autoria de Bergson. Uma pista interessante presente no acervo é notar que Pessoa possuía um exemplar do livro Quests Old and New de George Robert Stow Mead. O capítulo XII dessa obra, dedicada a alguns pensadores, ocupa-se justamente de Bergson, intitulando-se "Bergson's intuitionism". ${ }^{6}$

Já as menções do próprio Pessoa ao filósofo são ainda mais escassas. Porém, uma delas é bastante significativa, a que se encontra em um breve texto (ou fragmento) intitulado "A aliança ibérica". Ainda que citado entre parênteses, Bergson é aí colocado como "um dos três grandes filósofos da Europa contemporânea" quando Pessoa fala da necessidade de uma nova literatura e uma nova filosofia em Portugal. Eis o trecho: "Criar uma nova literatura, uma nova filosofia - esse é o primeiro passo. Foi dado em Portugal, em filosofia sobretudo, por Leonardo Coimbra, um dos três grandes filósofos da Europa contemporânea (os outros dois são Bergson e Eucken).” (PESSOA, 1980, p. 15)

Pessoa colocará Bergson uma outra vez ao lado de Eucken - no entanto em um contexto menos elogioso -, no poema-manifesto de Álvaro de Campos, o "Ultimatum" (publicado primeiramente na revista Portugal Futurista, 1917), quando ele diz, no tom enfático, irônico e militante, que compõe o texto: "Passai à esquerda do meu Desdém

\footnotetext{
${ }^{6}$ Devo a Antonio Cardiello, pesquisador da Casa Fernando Pessoa, em Lisboa, a localização dessa informação. Site em que a obra encontra-se digitalizada e disponível para download: http://casafernandopessoa.cm-lisboa.pt/bdigital/index/index.htm
} 
virado à direita, criadores de «sistemas filosóficos», Boutroux, Bergsons, Euckens, hospitais para religiosos incuráveis, pragmatistas do jornalismo metafísico, lazzaroni da construção meditada!" (PESSOA, 1980, p. 62).

Humor ou pose à parte, o que interessa ao propósito do presente estudo é notar a menção a Bergson, que não seria gratuita e que, ao contrário das menções geralmente críticas e desgostosas, feitas por Pessoa a Nietzsche, esboça uma certa simpatia ao filósofo em uma delas. Talvez comprovar que Pessoa tenha lido Bergson seja apenas uma curiosidade, uma peça a mais no quebra-cabeças a ser montado acerca da teoria pessoana. Mas o fato é que sua concepção acerca da sensação evidencia uma proximidade à concepção bergsoniana e, poderíamos sugerir, sintoniza a poética de Pessoa com toda uma gama de pensadores contemporâneos, levando-o para um pensamento que poderíamos dizer pós-fenomenológico. É o que talvez justifique a proximidade encontrada por José Gil, em seus diversos estudos, entre Pessoa e Deleuze, um filósofo que certamente Pessoa não leu (uma vez que nasceu em 1935, ano da morte do poeta) mas que, no entanto, parece conhecer intimamente, ou no íntimo de suas sensações.

\section{Bibliografia}

BALTRUSCH Burghard. "Filosofia e estética em Fernando Pessoa". In: Homenagem a Fernando Pessoa (Actas \& Colóquios; 19). Ed. Fernando Mão de Ferro. Lisboa: Edições Colibri, 1999, p.71-85.

BERGSON, Henri. Essai sur les données immédiates de la conscience. Paris: PUF, 2003.

Memória e vida. Textos escolhidos por Gilles Deleuze. Trad. Claudia Berliner. São Paulo: Martins Fontes, 2006.

COELHO, Eduardo Prado. A mecânica dos fluidos. Lisboa: Imprensa Nacional Casa da Moeda, 2012.

GIL, José. Diferença e negação na poesia de Fernando Pessoa. Rio de Janeiro: Relume Dumará, 2000.

. Fernando Pessoa ou a metafísica das sensações. Lisboa: Relógio D’Água, 1996. . O espaço interior. Lisboa: Presença, 1994.

PESSOA, Fernando. Livro do desassossego, vol.I. Org. Teresa Sobral Cunha. Coimbra: Presença, 1990. 
- Obra poética. Rio de Janeiro: Nova Aguilar, 2005.

- Páginas Íntimas e de Auto-Interpretação. Org. Georg Rudolf Lind e Jacinto do Prado Coelho. Lisboa: Ática, 1966.

Textos Filosóficos, Vol. II. Fernando Pessoa. Org. António de Pina

Coelho. Lisboa: Ática, 1968.

. Ultimatum e Páginas de Sociologia Política. Org. Maria Isabel Rocheta e

Maria Paula Morão. Intro. Joel Serrão. Lisboa: Ática, 1980.

RODRIGUES, Rodrigo Fonseca. "A poética como pensamento da sensação. Cognitio Estudos. São Paulo, vol. 4, n. 2, julho-dezembro, 2007, p. 160-164. 